\title{
Effect of An Educational Program on Cognitive Functions Among Elderly People Attending Outpatient Clinics At Assiut University Hospital
}

\author{
Heba M. Fahmy ${ }^{*}$, Hoda D. Fahmy ${ }^{* *}$, Alaa El-Din M. Darweesh ${ }^{* * *}$ and Asmaa \\ G. Mohammed ${ }^{* * *}$ \\ * Assistant Lecturer Of Geriatric Nursing, Faculty of Nursing, Assiut University. \\ ** Professor of Community Health Nursing, , Faculty of Nursing, Assiut University. \\ *** Professor Of Psychiatry, Faculty of Medicine, Assiut University. \\ ****Assistance Professor of Community Health Nursing, Faculty of Nursing, Assiut University.
}

\begin{abstract}
Educational programs increases elderly' knowledge of health care and makes them informed about their health care choices and help to keep older adults' lives active, delay going to nursing homes and increase satisfaction with life.

Aim of the study: assess knowledge, implement and evaluate educational program for elderly people about cognitive functions.

Material and Methods: the study was carried out using Quasi-experimental research design and included 100 elderly patients have normal cognitive functions, they selected randomly to participate in the program and recruited from outpatient clinics of Assiut University Hospital, they aged 60 years and older, and were selected by non- probability quota sample from the first of July 2012 until the end of February 2014. They screened by Mini Mental State Examination (MMSE) for cognitive functions, they also were assessed for their sociodemographic characteristics. The participant received knowledge about cognitive functions after pre-test evaluation, they also evaluated after receiving the program and three months later.

Results: The present study shows that there was a significant improvement of experimental group knowledge in post-test and three months later.

Conclusion: In spite of increased knowledge of elderly about cognitive functions and its promotion, there is no impact on their scores of MMSE after three months.

Recommendations: Periodical educational programs for elderly people to increase their awareness about cognitive functions.
\end{abstract}

Keywords: elderly, cognitive functions, cognitive impairment

\section{Introduction}

Older adults are generally defined as individuals' age 60 years and older. They are the fastest growing segment of the population world-wide. Globally, the number of persons aged 60 years and older is expected to almost triple within the next few decades, from 672 million in 2005 to nearly 1.9 billion by year 2050 (PerelLevin, 2008 and Miller, 2009).

Educational programs and health education increases individuals' knowledge of health and health care and makes them informed about their health care choices. World Health Organization (WHO) has emphasized the importance of Educational programs and health education to support health care needs and health promotion for elderly people (Kececi and Bulduk, 2012).

Cognitive function begins to decline from the age of 50 and accelerates after the age of 65 years. Cognitive impairment is common among elderly and increases with aging. (Angevaren et.al., 2008 and Fossati et.al., 2011). It does not only threaten the quality of life of older people, but also has negative impact on their caregivers, as well as representing challenges in different clinical care settings (Sweed \& Elawam, 2010). Conditions in which cognitive functioning is impaired include dementia, Alzheimer's, delirium, and depression (American Psychiatric Association, 2000).

Cognitive function is also influenced by other conditions like female sex, low education, a clinical history of stroke, tobacco smoking, alcohol consumption, physical inactivity, depression, and lack of social support (Anstey et.al., 2007; Fossati et.al., 2011).

Early recognition of cognitive impairment is important for diagnosis of potentially reversible medical conditions, and initiation of treatment interventions. Patients and caregivers will have time to prepare for lifestyle changes and plan for the future (Miller, 2009; Sweed \& Elawam, 2010).

Nurse practitioners who work in a variety of practice settings commonly provide care to the older adults with varying levels of cognitive ability. Although nurses are trained to recognize and provide care to 
patients with dementia, it is also important to recognize patients who are experiencing mild cognitive impairment (Elliott et. al., 2008).

\section{Significance of the Study}

Cognitive impairment including dementia is a growing worldwide public health problem, and its prevalence in elderly persons is between $10 \%$ and $22 \%$ (Etgen et.al., 2010). In Egypt, the prevalence of cognitive impairment was $20.9 \%$ among residents of the elderly homes in Cairo (Sweed \& Elawam, 2010). The prevalence of dementia was $4.5 \%$ in Assuit governorate-Egypt (Farrag et.al., 1998); and in Sharkia governorateEgypt, was 3.66\% (Zaitoun et.al., 2008).

Aim of the study:

To assess the knowledge of elderly people about cognitive functions, implement and evaluate educational program about cognitive functions.

\section{Research Design:}

\section{Materials And Method}

The study was carried out using Quasi-experimental research design, which is appropriate to the aim of the study that used to estimate the causal impact of an intervention on its target population.

\section{Study Setting:}

This study was conducted at out patient's clinics (i.e. ophthalmology, diabetes, cardiology, internal medicine clinics) in Assiut University Hospital, which is largest hospital in Upper Egypt and one of the biggest University Hospitals in Egypt.

\section{Study sample:}

Screening phase: -This study is the second phase of large screening sample chosen through non- probability quota sample technique to detect incidence of cognitive impairment among elderly people who aged 60 years and more and attended outpatient clinics of Assiut University Hospital.

Implementation phase: - This phase included one hundred elderly people, who have normal cognitive functions were selected. They were divided to two groups (each group $=50$ elderly patient), one for experimental group and the other for control group.

\section{Inclusion criteria:}

Elderly patients aged 60 years and more of both sexes who were attended outpatient clinics (i.e. ophthalmology, diabetes, cardiology, internal medicine clinics) of Assiut University Hospital.

- $\quad$ Elderly people who have normal cognitive functions (a score more than or equal to 24 out of 30 among educated people and more than or equal 22 out of 30 among illiterate according to MMSE).

- $\quad$ Accept to participate in the study.

Tools of the study: two tools were used for data collection:-

1: Structured interview questionnaire sheet:

A specially designed sheet was used for data collection. It included two parts:

Part one: it included sociodemographic characteristics as age, sex, marital status, education, occupation, residence, social assistance, family size, and family type for experimental and control group.

Part two: it includes (Pre-test, Post-test and follow-up) sheet: It used to assess the knowledge of participants before and post implementation of the program. And follow up evaluation was carried out 3 months later.

The Educational program score was the sum of correct responses to 8 questions (56 items). One grade was given for the correct answer and zero for the wrong answer. Components' scores included definition of cognitive functions (7 items), age-related changes in cognitive functions (6 items), cognitive disorders (4 items), signs and symptoms of Dementia and Alzheimer (6 items), signs and symptoms of Delirium (9 items), signs and symptoms of Depression (9 items), risk factors of cognitive impairment ( 7 items), and health promotion of cognitive functions ( 8 items).

\section{2-The Mini-mental status examination (MMSE)(Folstein et. al., 1975)}

The Mini-Mental State Examination (MMSE) is a widely used, well-validated screening tool for evaluation of cognitive impairment. The MMSE was used to assess cognitive function.

Assessment of the cognitive status by using the Arabic version of the Mini Mental state examination (MMSE). It briefly measures orientation to time and place (score=10), short-term verbal memory $($ score $=3$ ), 
attention and calculation (score=5), immediate recall (score=3), and language (score=9). The total score of MMSE is 30, a score less than 24/30 indicates cognitive impairment among educated people and less than 22/30 among illiterate subjects.

\section{The Educational Program:}

The educational program has been developed by researcher after reviewing the relevant literatures and revised \& corrected by supervisors.

\section{The program included 2 parts:}

A) Theoretical part:- It Include definition of cognitive functions, age-related changes in cognitive functions, cognitive disorders (Alzheimer, Dementia, Delirium, and Depression), risk factors of cognitive impairment, Health promotion of cognitive functions which include (healthy diet, habits that can damage the brain, physical exercises that is recommended to the elderly, and mental exercises)

B) Practical part: - It Include mental training exercise and physical exercises

Program teaching methods: Teaching methods included in this program were lectures, discussion, and demonstration. Handout and posters were used. The program was given individually, as it was difficult to meet all the subjects at same time.

\section{Schedule of the program}

A) Experimental group (50 elderly): Each participant was subjected to:

1- Assessment (pre-test) stage: This phase assessed the elder's knowledge about cognitive functions and their MMSE.

2- Implementation stage: The educational program provided only for experimental group (50 elderly)

\section{Time and number of sessions:}

The program was given individually and given in two sessions (1 hour for each session).

1. The first session was included definition of cognitive functions, age related changes of cognitive functions, cognitive impairment, risk factors of cognitive impairment.

2. The second session was included health promotion of cognitive function such as nutrition, early diagnosis and treatment of risk factors, social engagement, physical exercises, and mental activities.

3. Evaluation of the impact of the program (Immediate Post-test) stage: This phase was carried out only for experimental group to assess the elder's knowledge about cognitive functions immediately after the program (post-test).

4. Evaluation of the impact in follow up stage: This phase was carried out three months later to assess the elder's knowledge about cognitive functions and their MMSE.

B) Control group (50 elderly): Each participant was subjected to:

1- Assessment (pre-test) stage: This phase assessed the elder's knowledge about cognitive functions and their MMSE.

2. Follow up stage: This phase was carried out three months later to assess the elder's knowledge about cognitive functions and their MMSE.

\section{Pilot study:}

Pilot study was carried out before starting data collection on (10 elderly patients), who were not included in the study. The aim of pilot study is to test the clarity and applicability of the tool and to assess the respondent's acceptance and understanding of the questions, and the required modifications were performed.

\section{Ethical considerations}

The study was approved by the ethical committee of Faculty of Nursing Assiut University. Oral consent from elderly patients for participation in the study was obtained. Full explanation about the purpose of the study was discussed with the patients before starting data collection. Confidentiality of the information was maintained during the steps of the study. No harm to the participant was expected during all steps of the study. Patient was informed about the result of the test. 
Data collection phase:

The researcher met the elderly, explained the purpose of the study, and asked for participation. She started a face to face individual interview with elderly, completed the sheet for all persons and wrote exactly the answers that the elderly persons given. Interview was take place at outpatient clinic.

Data was collected on average of two days weekly; with an average number of 1-2 elderly interviewed per day during the assessment of their cognitive functions, the approximate time spent for filling the questionnaire sheet was around 30-45 minutes for filling of the structured interview questionnaire, and one hour for each session.

The patients were recruited during the period from the first of July 2012 until the end of February 2014.

\section{Statistical analysis}

The obtained data were reviewed, prepared for computer entry, coded, analyzed and tabulated. Descriptive statistics (frequencies, percentage, and mean) were done using computer program SPSS version 16 (SPSS, 2009). Chi-square test, independent sample t-test, paired samples t-test, were used for analysis of variance.

\section{Results}

Table (1): Distribution of demographic characteristics for experimental and control group (n=100).

\begin{tabular}{|c|c|c|c|c|}
\hline \multirow[t]{2}{*}{ Socio demographic characteristics } & \multicolumn{2}{|c|}{$\begin{array}{l}\text { Experimental } \\
\operatorname{Group}(n=50)\end{array}$} & \multicolumn{2}{|c|}{$\begin{array}{l}\text { Control Group } \\
(n=50)\end{array}$} \\
\hline & No. & $\%$ & No. & $\%$ \\
\hline \multicolumn{5}{|l|}{ Age: } \\
\hline$<65$ years & 42 & 84.0 & 37 & 74.0 \\
\hline$\geq 65$ years & 8 & 16.0 & 13 & 26.0 \\
\hline \multicolumn{5}{|l|}{ Sex: } \\
\hline Male & 21 & 42.0 & 21 & 42.0 \\
\hline Female & 29 & 58.0 & 29 & 58.0 \\
\hline \multicolumn{5}{|l|}{ Residence: } \\
\hline Urban & 2 & 4.0 & 3 & 6.0 \\
\hline Rural & 48 & 96.0 & 47 & 94.0 \\
\hline \multicolumn{5}{|l|}{ Marital status: } \\
\hline Married & 37 & 74.0 & 34 & 68.0 \\
\hline Widow & 13 & 26.0 & 16 & 32.0 \\
\hline \multicolumn{5}{|l|}{ Level of education: } \\
\hline Not educated & 39 & 78.0 & 46 & 92.0 \\
\hline Educated & 11 & 22.0 & 4 & 8.0 \\
\hline \multicolumn{5}{|l|}{ Occupation: } \\
\hline Farmer & 19 & 38.0 & 17 & 34.0 \\
\hline Skilled worker & 0 & 0.0 & 1 & 2.0 \\
\hline Free business & 1 & 2.0 & 2 & 4.0 \\
\hline Housewife & 29 & 58.0 & 29 & 58.0 \\
\hline Retired & 1 & 2.0 & 1 & 2.0 \\
\hline \multicolumn{5}{|l|}{ Social assistance: } \\
\hline Yes & 21 & 42.0 & 32 & 64.0 \\
\hline No & 29 & 58.0 & 18 & 36.0 \\
\hline \multicolumn{5}{|l|}{ Living condition: } \\
\hline Lives alone & 1 & 2.0 & 4 & 8.0 \\
\hline Lives with family & 49 & 98.0 & 46 & 92.0 \\
\hline \multicolumn{5}{|l|}{ Family type: } \\
\hline Nuclear & 15 & 30.0 & 9 & 18.0 \\
\hline Extended & 35 & 70.0 & 41 & 82.0 \\
\hline
\end{tabular}

Table (2): Score of Mini Mental State Examination (MMSE) for program studied sample (experimental and control group).

\begin{tabular}{|c|c|c|c|c|c|c|}
\hline \multirow[t]{3}{*}{ MMSE Domains } & \multicolumn{3}{|c|}{ Experimental group } & \multicolumn{3}{|c|}{ Control group } \\
\hline & Pre-test & Follow up & P-value & Pre-test & Follow up & P- \\
\hline & Mean \pm SD & Mean \pm SD & & Mean \pm SD & Mean \pm SD & value \\
\hline Orientation & $9.20 \pm 0.97$ & $8.72 \pm 0.88$ & 0.011* & $9.14 \pm 0.95$ & $8.66 \pm 0.91$ & 0.014* \\
\hline Registration & $3.00 \pm 0.00$ & $3.00 \pm 0.00$ & -- & $3.00 \pm 0.00$ & $3.00 \pm 0.00$ & -- \\
\hline $\begin{array}{l}\text { Attention and } \\
\text { calculation }\end{array}$ & $5.00 \pm 0.00$ & $5.00 \pm 0.00$ & -- & $5.00 \pm 0.00$ & $5.00 \pm 0.00$ & -- \\
\hline Recall & $2.64 \pm 0.60$ & $2.34 \pm 0.56$ & 0.001* & $2.66 \pm 0.75$ & $2.14 \pm 0.60$ & 0.000* \\
\hline Language & $6.44 \pm 1.26$ & $6.06 \pm 0.31$ & $0.042 *$ & $6.14 \pm 0.57$ & $6.18 \pm 0.56$ & 0.725 \\
\hline $\begin{array}{l}\text { Total score of } \\
\text { MMSE }\end{array}$ & $26.28 \pm 1.84$ & $25.12 \pm 0.82$ & $0.000 *$ & $25.94 \pm 1.45$ & $24.98 \pm 1.29$ & 0.001* \\
\hline
\end{tabular}


${ }^{(*)}$ There is a significant difference

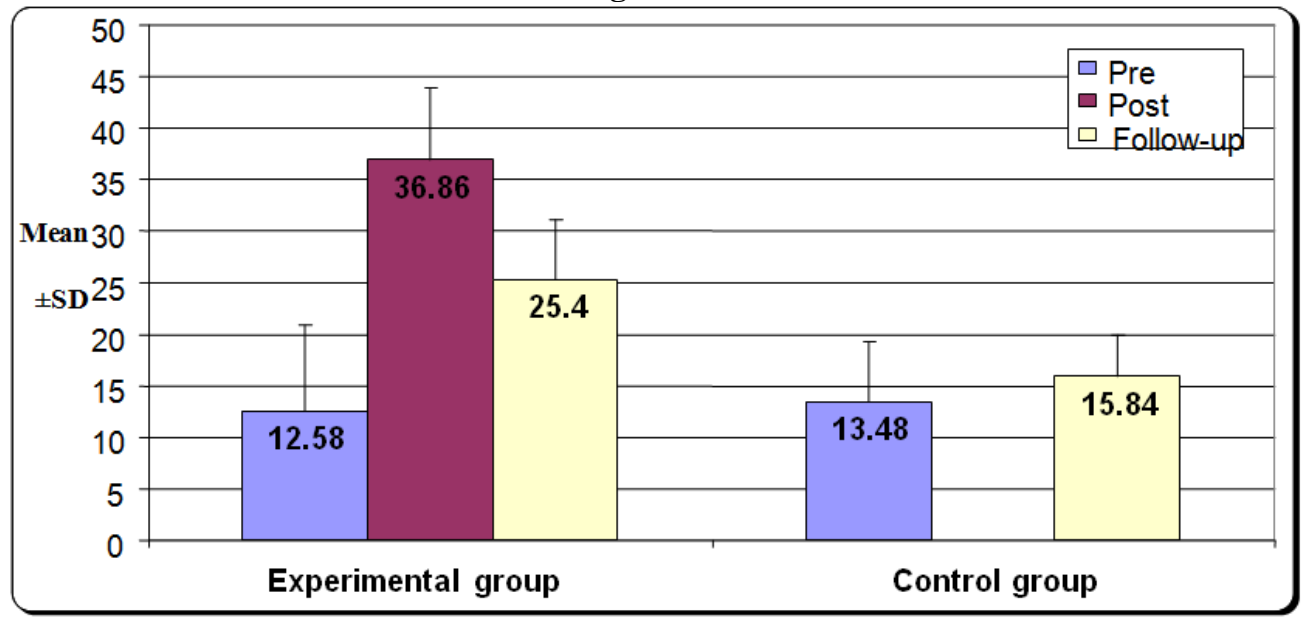

Figure (1) Educational program mean scores for experimental group and control group regarding cognitive functions.

Table (3): Educational program mean scores for experimental group and control group regarding cognitive functions.

\begin{tabular}{|c|c|c|c|c|c|c|c|}
\hline Group & Mean scores & Pre-test & Post-test & Follow-up & $\begin{array}{l}\text { P-value } \\
\text { (1) }\end{array}$ & $\begin{array}{c}\text { P-value } \\
\text { (2) }\end{array}$ & $\begin{array}{c}\text { P-value } \\
\text { (3) }\end{array}$ \\
\hline \multirow{2}{*}{$\begin{array}{l}\text { Experimental } \\
\text { Group }\end{array}$} & Mean \pm SD & $12.58 \pm 8.32$ & $36.86 \pm 7.10$ & $25.40 \pm 5.72$ & \multirow[t]{2}{*}{$0.000 *$} & \multirow[t]{2}{*}{$0.000^{*}$} & \multirow[t]{2}{*}{$0.000 *$} \\
\hline & Range & $0.0-30.0$ & $24.0-49.0$ & $4.0-35.0$ & & & \\
\hline \multirow[t]{2}{*}{ Control group } & Mean \pm SD & $13.48 \pm 5.75$ & -- & $15.84 \pm 4.16$ & \multirow[t]{2}{*}{--} & \multirow[t]{2}{*}{--} & \multirow[t]{2}{*}{$0.024 *$} \\
\hline & Range & $5.0-28.0$ & -- & $7.0-29.0$ & & & \\
\hline P-value & & 0.536 & & $0.000 *$ & & & \\
\hline
\end{tabular}

P-value (1) = relation between pre-test score and post test score

P-value (2) = relation between post test score and follow-up score

P-value (3) = relation between pre-test score and follow-up score

Table (1): Distribution of demographic characteristics for experimental and control group, it was observed that $84.0 \%$ of the experimental group aged $60-65$ years, $58.0 \%$ were female, $96.0 \%$ lived in rural area, $74.0 \%$ were married, $78.0 \%$ were not educated, $58.0 \%$ were house wife, $98.0 \%$ live with their family and $70.0 \%$ live in extended family. Also, table shows, that $74.0 \%$ of control group aged $60-65$ years, $58.0 \%$ were female, $94.0 \%$ lived in the rural area, $68.0 \%$ were married, $92.0 \%$ were not educated, $58.0 \%$ were house wife, $92.0 \%$ live with their family and $82.0 \%$ live in extended family.

Table (2) Score of Mini Mental State Examination (MMSE) for program studied sample (experimental and control group), it was observed that there is statistical significant decrease of total scores of MMSE of both experimental and control group in the follow up test. However they are still within normal ranges.

Table (3) and figure (1): Educational program mean scores for experimental group and control group regarding cognitive functions, it was observed that regarding to educational program mean scores for experimental group and control group about their knowledge of cognitive functions, there are non significant differences between them at the pretest evaluation $(\mathbf{P}=\mathbf{0 . 5 3 6})$. In the immediate post-test evaluation, the experimental group has significantly higher mean scores than their mean scores in the pre-test $(\mathbf{P}=\mathbf{0 . 0 0 0})$. However, this score was significantly decrease on the evaluation 3 months later $(\mathbf{P}=\mathbf{0 . 0 0 0})$, but still higher than that in the pre-test phase. Comparing the mean scores of knowledge for experimental group and control group 3 months later after the study, the experimental group has significantly higher mean scores than the control group (P=0.000).

\section{Discussion}

Cognitive impairment is common among older adults. In the present study the researcher assess cognitive functions and determine prevalence of cognitive impairment among elderly people. Regarding socio demographic characteristics of the studied population, it was found that $84.0 \%$ of the experimental group and $74.0 \%$ of control group aged 60-65years, $58.0 \%$ of both group were female, $96.0 \%$ of the experimental group and $94.0 \%$ of control group lived in rural area, $74.0 \%$ of the experimental group and $68.0 \%$ of control group 


\section{Effect Of An Educational Program On Cognitive Functions Among Elderly People Attending ...}

were married, $78.0 \%$ of the experimental group and $92.0 \%$ of control group were illiterate, $58.0 \%$ of both group were house wife and only $2.0 \%$ of the experimental group and $8.0 \%$ of control group live alone.

These results are similar to that reported by the study conducted by Shehatah et.al., (2009) who studied the prevalence of depression and association of cognitive impairment in elderly in suburban community in Egypt and reported that the mean age of participants was $66.16 \pm 5.62$ years, $52.3 \%$ were females and $47.7 \%$ were males, $67.4 \%$ were married, $89.5 \%$ were not educated, and $16.3 \%$ lived alone.

Also, the present study agrees with Sweed and Elawam (2010) who study cognitive impairment among residents of elderly homes in Cairo, Egypt and reported that participants had a mean age of $74.4 \pm 8.3$ years, $57.7 \%$ of participants were females and $42.3 \%$ were males. On the other hand, our study disagrees with them in reporting that only $4.1 \%$ of participants were married, and $39.9 \%$ were illiterate.

Also, the study agrees with Fossati et.al., (2011) who study a self-administered questionnaire to screen the risk of dementia, and found that the mean age of participants was $71.04 \pm 6.62$ years, $55.9 \%$ were females and $44.1 \%$ were males, and $66.3 \%$ were married. In the other hand, our study disagrees with them in reporting that only $1 \%$ of participants were illiterate and only $15.9 \%$ were housewives.

Regarding to educational program mean scores for experimental group, it was noticed that the improvement of the knowledge of elderly about cognitive functions that occurred after application of the program is not maintained three months later.

This is related to that memory changes are the most common cognitive complaints among older adults. Memory consolidation is affected by aging process. It is the process by which memory traces of encoded information are strengthened, stabilized and stored to facilitate later retrieval. The process of consolidation is subject to reorganization when new, relevant information is learned. The elderly people may have age-related changes in cognitive functions such as forgetfulness and decrease the ability to concentrate and they have chronic illness such as DM and hypertension which negatively affect cognitive functions.

Inspite of increased knowledge of elderly about cognitive functions and its promotion, there is no impact on scores of MMSE after three months (follow-up phase). This may related to the fact that application of educational program had barriers to be effective such as the elderly commonly have physical, psychological, and socio-cultural changes, short-term memory loss, visual and hearing changes, sleep disorders, and chronic illness.

The improvement of knowledge of elderly about cognitive functions without improvement of their objective measures of cognitive functions is reported by other authors. Troyer et.al., (2008) study changing everyday memory behavior in amnestic mild cognitive impairment, and found that those who received training in practical, everyday memory techniques increased knowledge and use of memory strategies from pre-test to immediate post-test, and these gains were maintained at three-month post-test relative to controls but do not affect on memory test performance compared to a control group.

Rapp et.al., (2002) study memory enhancement training for older adults with mild cognitive impairment and found that memory training improved perceptions of memory capabilities but not objective measures of memory performance compared with a no-trained control group. Also, Craik et.al., (2007) studied the effects of a 12-week cognitive rehabilitation training program on memory performance in older adults. In the memory Training module, participants were instructed on the nature of memory and how to improve memory performance; internal and external strategies were described and practiced over the training sessions. The authors found that there was no training-related improvement in working memory, primary memory, or recognition memory.

Other studies have reported that various cognitive training programs are associated with significant improvements in cognitive outcomes. Ball et.al., (2002) studied effects of cognitive training interventions with older adults, found that there was effective of the cognitive training interventions in improving cognitive abilities, and the proximal training effects occurred, as the follow-up were through 24 months, and that a significant segment of trained individuals went forward through 2 years of life with better cognitive skills than did the controls.

Belleville et.al., (2006) studied improvement of episodic memory in persons with mild cognitive impairment and healthy older adults, and found that significant pre-post effect on measures of subjective memory and well-being. There was no improvement in the performance of groups of elderly persons who did not receive the intervention. Günther et.al., (2003) studied long-term improvements in cognitive performance through computer-assisted cognitive training, and found that after the cognitive training program there were significant improvements in primary and secondary working memory. They suggested that computerized cognitive training programs could be used in older people to achieve long-term improvements and computers could be employed more extensively to prevent and treat cognitive deficits in older people. 


\section{Effect Of An Educational Program On Cognitive Functions Among Elderly People Attending ...}

\section{Conclusion}

In spite of increased knowledge of elderly about cognitive functions and its promotion, there is no impact on their scores of MMSE after three months.

\section{Recommendations} functions.

Periodical educational programs for elderly people to increase their awareness about cognitive

\section{References}

[1]. American Psychiatric Association (APA), (2000): Diagnostic and statistical manual of mental disorders, $4^{\text {th }}$ ed., Washington

[2]. Angevaren M., Aufdemkampe G., Verhaar H.J., Aleman A., and Vanhees L., (2008): Physical activity and enhanced fitness to improve cognitive function in older people without known cognitive impairment. Cochrane Database Syst. Rev. 3, CD005381.

[3]. Anstey K.J., Von-Sanden C., Salim A., and O'Kearney R., (2007): Smoking as a risk factor for dementia and cognitive decline: a meta-analysis of prospective studies. Am. J. Epidemiol. 166, 367-378.

[4]. Ball K., Berch D.B., Helmers K.F., Jobe J.B., Leveck M.D., Marsiske M., Morris J.N., Rebok G.W., Smith D.M., Tennstedt S.L., Unverzagt F.W., and Willis S.L., (2002): Effects of cognitive training interventions with older adults: a randomized controlled trial. JAMA.; 288(18):2271-81.

[5]. Belleville S., Gilbert B., Fontaine F., Gagnon L., Ménard E., and Gauthier S., (2006): Improvement of episodic memory in persons with mild cognitive impairment and healthy older adults: evidence from a cognitive intervention program, Dement Geriatr Cogn Disord.;22(5-6):486-99. Epub 2006 Oct 16.

[6]. Craik F.I., Winocur G., Palmer H., Binns M.A., Edwards M., Bridges K., Glazer P., Chavannes R., and Stuss D.T., (2007): Cognitive rehabilitation in the elderly: Effects on memory, Journal of the International Neuropsychological Society / Volume 13 / Issue 01, pp 132-142.

[7]. Elliott A.F., Horgas A.L., and Marsiske M., (2008): NURSES' ROLE IN IDENTIFYING MILD COGNITIVE IMPAIRMENT IN OLDER ADULTS, Geriatr Nurs.; 29(1): 38-47.

[8]. Etgen T., Sander D., Huntgeburth U., Poppert H., Förstl H., and Bickel H., (2010): Physical Activity and Incident Cognitive Impairment in Elderly Persons, Arch Intern Med., 170(2):186-193.

[9]. Farrag A.F., Farwiz H.F., Khedr E.M., and Mahfouz R.M., (1998): Prevalence of Alzheimer's disease and other dementing disorders: in Assiut-Upper Egypt Study. Dement and Geriatr Cogn Disord.; 9: 322-8.

[10]. Folstein M.F., Folstein S.E., and McHugh P.R., (1975): Mini-Mental State: A practical method for grading the cognitive state of patients for the clinician. J Psychiat Res 12: 189-198.

[11]. Fossati C., De Benedetto G.A., Leboffe C., Marigliano B., Mancinella M., Ettorre E., and Marigliano V., (2011): A selfadministered questionnaire to screen the risk of dementia: A pilot study and the results of a comparison with the mini-mental state examination (MMSE), Archives of Gerontology and Geriatrics, 1-5

[12]. Günther V.K., Schäfer P., Holzner B.J., and Kemmler G.W., (2003): Long-term improvements in cognitive performance through computer-assisted cognitive training: a pilot study in a residential home for older people, Aging Ment Health.; 7(3):200-6.

[13]. Kececi A. and Bulduk S., (2012): Health Education for the Elderly, Geriatrics, ISBN: 978-953, pp 251-253

[14]. Available from: http://www.intechopen.com/books/geriatrics/health-education-for-elderly-people

[15]. Miller C. A., (2009): Nursing for Wellness in Older Adult, 5th edition, Chapter 11, p.p. 192, 196, chapter 14, 273-280

[16]. Perel-Levin S., (2008): Discussing Screening for Elder Abuse at Primary Health Care level, WHO, AGING AND LIFE COURSE.

[17]. Rapp S., Brenes G., and Marsh A.P., (2002): Memory enhancement training for older adults with mild cognitive impairment: a preliminary study. Aging Ment Health.; 6(1):5-11.

[18]. Shehatah A., El-Okda E., and Rabie M., (2009): Prevalence of Depression and Association of Cognitive Impairment in Elderly in Suburban Community in Egypt Current Psychiatry; Vol. 16 No.2:192-199).

[19]. SPSS inc., (2009): PASW Statistics for windows, version 16.0. Chichago

[20]. Sweed H.S. and Elawam A.E., (2010): Cognitive Impairment among Residents of Elderly Homes In Cairo, Egypt, MIDDLE EAST JOURNAL OF PSYCHIATRY AND ALZHEIMERS, Volume 1, Issue 1.

[21]. Troyer A.K., Murphy K.J., Anderson N.D., Moscovitch M., and Craik F.I., (2008): Changing everyday memory behaviour in amnestic mild cognitive impairment: a randomised controlled trial. Neuropsychol Rehabil.; 18:65-88.

[22]. Zaitoun A.M., Sarhan A.M., Selim A.M., and Mousa G.R., (2008): Epidemiological Study of Dementia after Retirement, Egypt J. Neurol. Psychiat. Neurosurg., 45(1): 65-74. 